\title{
Dynamic identification of a 1:5 scaled railway bogie on roller rig
}

\author{
N. Bosso, A. Gugliotta \& A. Somà \\ Politecnico di Torino, Dipartimento di Meccanica, Italy
}

\begin{abstract}
A Scaled Roller Rig is an experimental device to carry out laboratory tests on railway vehicles. The advantages of this method consist of low costs, low testing time and good repeatability. Different testing conditions, such as different friction, wear of profiles and axle load can be easily reproduced. Due to this reason many authors use roller rig to study railway dynamic, wear, noise and other railway problems. This work describes the experimental tests carried out to analyze the dynamical behaviour of a 1:5 scale railway bogie on a roller rig in tangent track conditions. The Roller Rig has been designed and realized at Politecnico di Torino and the first tests have been conducted on a single suspended wheelset.

Tests performed on a single wheelset are used to validate the wheel/rail and wheel/roller contact algorithm and to adjust the parameters of numerical models. On the other hand the study of a complete railway bogie allows one to simulate the behaviour of a real vehicle and can be used in the design phase of new vehicles. For instance, it is possible to evaluate the effect of changes brought to the suspension system on the running dynamics of the vehicle.
\end{abstract}

Keywords: wheel-rail, dynamics, contact, roller-rig.

\section{Introduction}

The use of Roller-Rig allows one to simulate the behaviour of real vehicles under well known testing conditions. If the tests are performed on reduced scale prototypes, it is possible to significantly reduce the costs.

Unfortunately the railway vehicle has a different behaviour on the track respect on Roller Rig, this is mainly due to finite curvature of the rollers, which modify the shape of the contact patch and add an instable gravitational effect 
during the yaw rotation of the wheelset. This primary effect leads to a higher instability of the wheelset on roller rig, depending on the roller radius (higher radius leads higher instability); this aspect can be analytically determined by modifying the equations governing the kinematical creepages $[6,8,10]$.

Because the shape of the contact area change due to the finite curvature of the rollers, it is possible to modify the transversal curvature of the roller in order to achieve the same shape. For example on figure 1, the elliptical contact area are shown for wheel-rail and wheel-roller contact, considering a conical wheel (0.3 rad) and a ratio $R_{\text {wheels }} / R_{\text {Roller }}=0.5$. The two shapes are different, but if the transversal curvature radius of the roller is modified $(0.025 \mathrm{~m}$ instead of $0.06 \mathrm{~m}$, in 1:5 scale), it is possible to obtain the same $\mathrm{a} / \mathrm{b}$ ratio again.
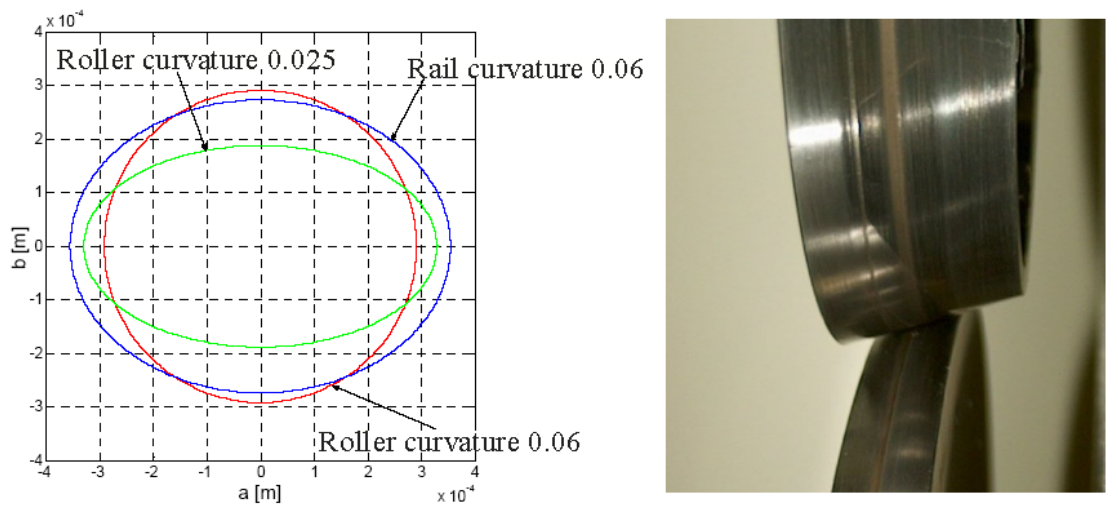

Figure 1: Different contact shape considering a conical $(0.3 \mathrm{rad})$ wheel over a rail (transversal curvature radius $0.06 \mathrm{~m})$ or a roller $(0.06 \mathrm{~m}$ and $0.025 \mathrm{~m})$.

Another effect, which differentiates the dynamic on roller rig respect to the dynamic on rails, is the fact that the contact point moves forward during yaw movement of the wheelset more on rollers than on rails (contact point shift [8]). This is negligible on straight track but becomes important during curving. For this reason, to simulate the curve behaviour on roller rig, it is required to supply to the rollers a number of controlled movements in order to keep each wheel on the top of the corresponding roller. Furthermore, on narrow curve, if the contact point shift produces a flange contact located forward respect the tread contact, this cannot be reproduced on a roller rig.

The roller rig built at Politecnico di Torino is used to perform dynamic simulations on straight track using a single wheelset and an entire bogie (2 axles). The prototypes are realized in reduced scale (1:4-1:5) and therefore it is required to use a similitude approach in order to convert the results obtained on the scaled prototype to the real vehicle.

The choice of the appropriate similitude law is not unique, and in general it is not possible to reproduce all the physical laws on a scaled model at the same time. In fact the scaling factors which relates the scaled quantity to the unscaled 
ones represents a linear relation and not all the phenomena involved are linear. In order to choose the most suitable law, different models proposed in literature have been analysed and compared [4]. The prototype has been designed according the similitude law proposed by Jaschinski [2], whose most important scaling factors are shown on table 1.

Table 1: $\quad$ Scaling factors according to Jaschinski’s similitude (1:5).

\begin{tabular}{lcc}
\hline \multicolumn{1}{c}{ Unit } & symbol & Scaling factor \\
\hline Length & $\varphi_{l}$ & 5 \\
\hline Time & $\varphi_{t}$ & $\sqrt{5}$ \\
\hline Velocity & $\varphi_{v}$ & $\sqrt{5}$ \\
\hline Acceleration & $\varphi_{a}$ & 1 \\
\hline Mass & $\varphi_{m}$ & 125 \\
\hline Inertia moments & $\varphi_{I}$ & 3125 \\
\hline Force & $\varphi_{F}$ & 125 \\
\hline Creep Forces & $\varphi_{T}$ & 125 \\
\hline Torque & $\varphi_{C}$ & 625 \\
\hline Friction Coefficient & $\varphi_{\mu}$ & 1 \\
\hline
\end{tabular}

The roller-rig has been realized using a modular approach, which allows one to simulate different types of vehicles; it is possible to modify the wheelset spacing (1.8-3.5 $\mathrm{m}$ in real scale), the axle load, the profiles conicity and the suspension characteristics (see fig. 2).

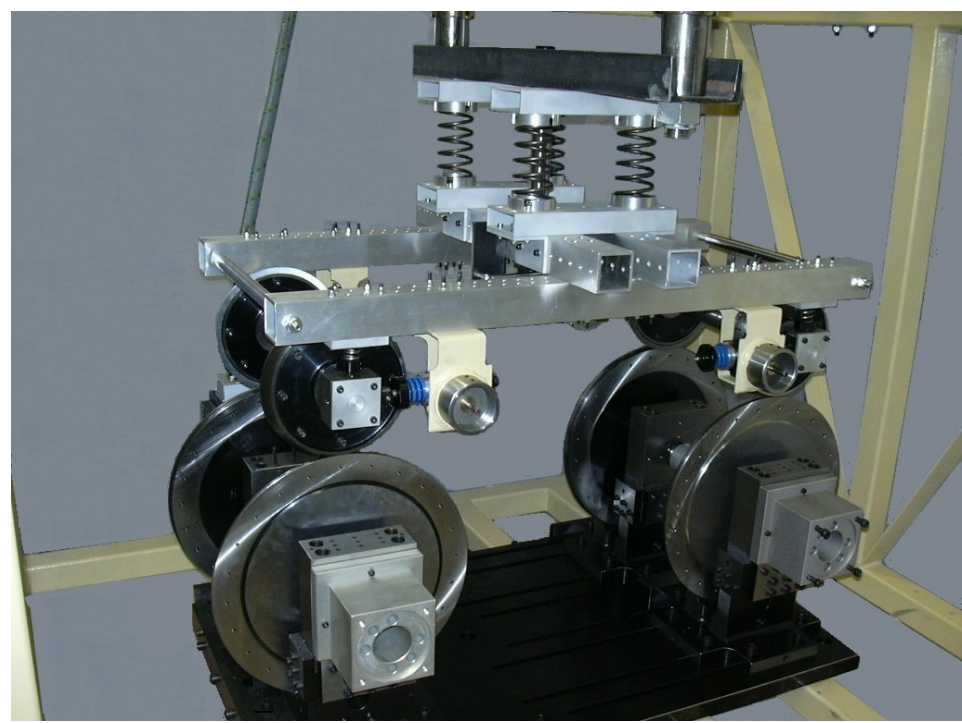

Figure 2: $\quad$ Roller Rig realized at Politecnico di Torino with a modular bogie. 


\section{Experimental device}

The Roller Rig can be used to test a bogie prototype (fig. 2); in this case each pair of rollers is used to support a wheelset of the bogie. The rollers are independent and can be moved in the longitudinal direction in order to fit with the spacing of the bogie. The bogie itself has been designed with variable wheelset spacing in the range $1.8-3.5 \mathrm{~m}$ in real scale, in order to simulate every kind of railway vehicle (freight - high speed).

The primary suspension system has been studied with separate stiffness and preload regulation for each direction (lateral, longitudinal and vertical), the stiffness is provided by helical springs which can be easily replaced.

The axle load can be modified with additional loads applied on the load beam which is located over the secondary suspension stage and can move only in the vertical direction. The longitudinal motion of the bogie respect to the rollers is constrained by a pair of anti-symmetric traction bars connecting the centre of the bogie with the external structure.

The roller rig has been used to carry on tests on a single wheelset (fig. 3), in this case only a pair of rollers is used. The wheelset is suspended using a support structure providing separate stiffness in longitudinal, vertical and lateral direction.

The preload can be regulated for each direction using a screw device which integrates an estensimetric system to measure the load.

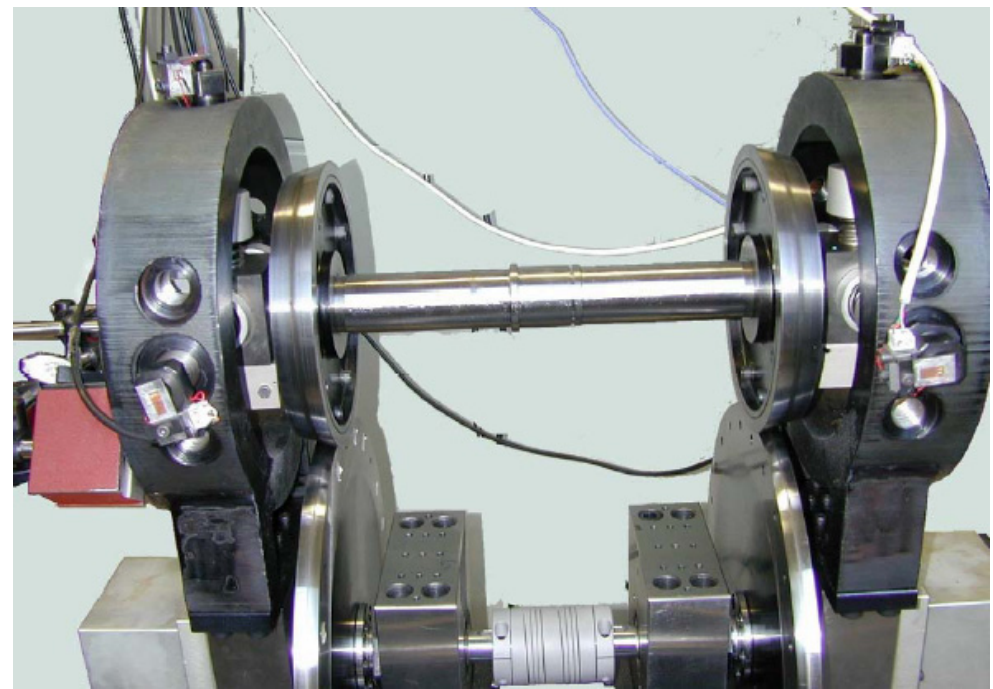

Figure 3: $\quad$ Testing device for a single wheelset.

\subsection{Measuring systems and experimental identification}

The measuring system is composed by accelerometers applied on the wheelset axle-box in longitudinal, lateral and vertical direction (fig. 4). In order to 
measure the wheelset displacement capacitive transducers are used in lateral and longitudinal direction (LVDT X and Y on fig. 4).

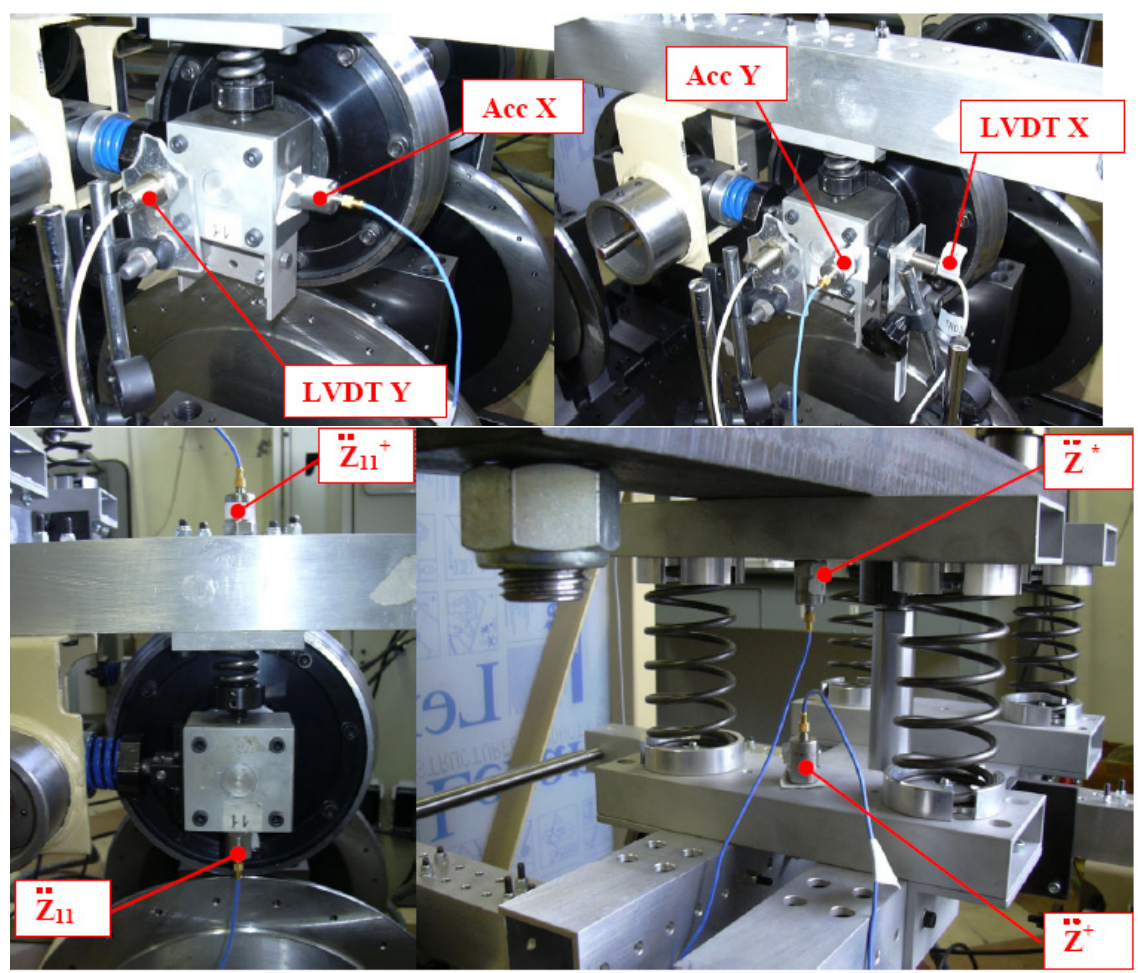

Figure 4: Accelerometers and displacement transducers.

Additional accelerometers have been mounted on the bogie frame and on the load beam in the vertical direction in order to measure the roller-coach transfer function. The forces acting on the suspension has been measured on the single suspended wheelset (fig. 1) while on the bogie an indirect measure has been done using estensimetric bridges applied on the bogie frame structure.

While in the case of the single wheelset tests, the "vehicle" characteristics can be easily identified (it simply consists on the inertial data and the shear and axial stiffness of the springs), in the case of the test on the bogie, the experimental identification is more complex.

The vehicle configuration used for the tests here described refers to a passenger high speed vehicle, with wheelset spacing equal t $2.7 \mathrm{~m}$, high values of the longitudinal $(\mathrm{Cx}=5 \mathrm{MN} / \mathrm{m})$ and lateral $(\mathrm{Cy}=10 \mathrm{MN} / \mathrm{m})$ stiffness. The prototype required an accurate identification of all the parameters, performed via a Modal Analysis on the bogie suspended (fig. 5 left) and mounted on the rollers. This analysis has been preceded by static and dynamic (fig. 5 right) identification of each spring and of mass and inertia of each component. 


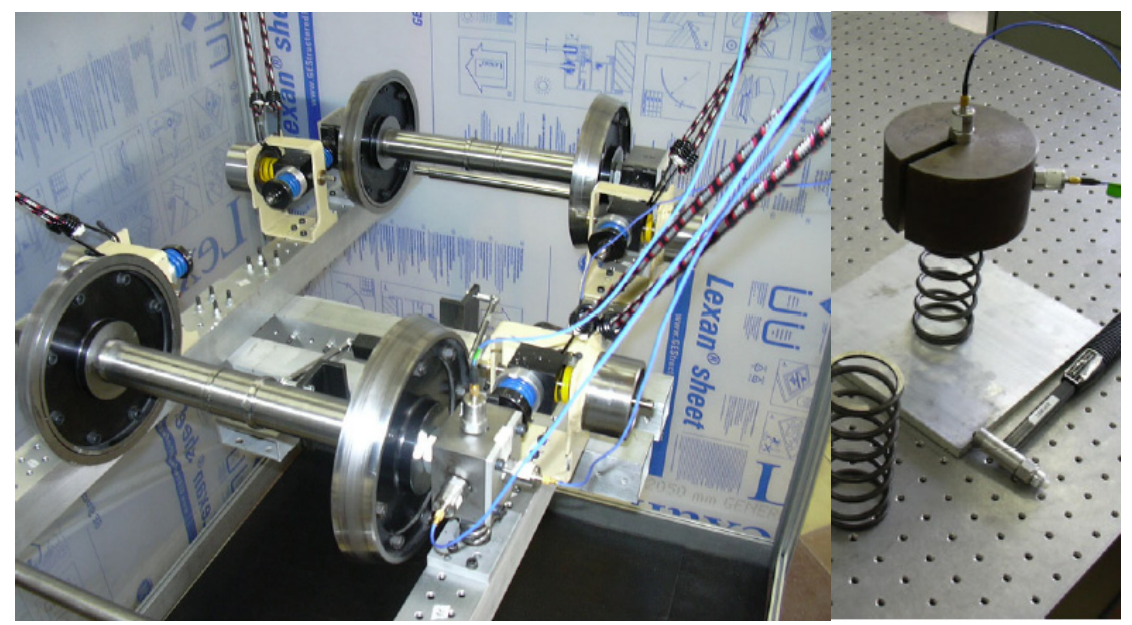

Figure 5: Modal analysis on the suspended bogie (left). Test on components (right).

\section{Numerical model}

In case of the single wheelset the numerical model is trivial regarding the vehicle description: the vehicle model is made of a single rigid body (the wheelset) constrained to the inertial system by the set of springs and to the rollers by the wheel-roller contact. This allows one to focus the attention on the contact problem.

The model of the single wheelset has been realized using a Multibody code (MSC/Adams see $[12,13]$ ) where the wheel-roller contact has been described by a formulation developed by the authors $[10,11]$.

To simulate the behaviour of the boogie, a model of an entire vehicle has been realized using a commercial Multibody code (Simpack). In this way it is possible to validate the vehicle model using the Roller-Rig and subsequently to use the model to predict the behaviour of the vehicle in situation which cannot be simulated $\mathrm{n}$ the roller-rig, such as curving.

Of course this choice does not allow one to obtain the same modelling flexibility of the first approach (the contact model can't be modified) and the results are expected to be less accurate. This is not a big limitation since in this case the interest is to perform optimization on the vehicle characteristics and only relative indications are necessary: e.g. it is useful to know if increasing the stiffness the critical speed increase or not, but it is not important to know the exact value of the critical speed. However a detailed model has been developed (fig. 6) using the data obtained by the experimental identification.

The models have been used in order to reproduce the same conditions of the experimental simulation performed on the roller-rig. With this aim a straight track has been used, but on the ideal track the irregularities detected on the rollers have been superimposed repeating N-times the envelope length of the rollers. 

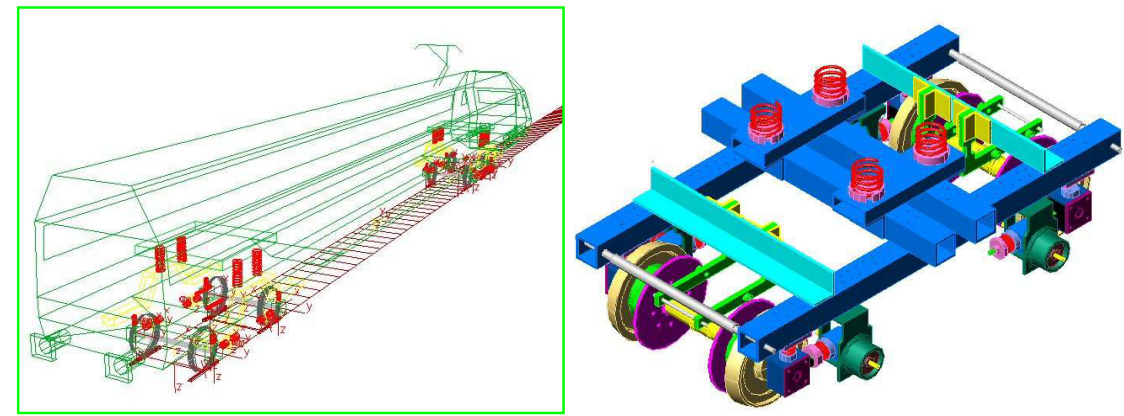

Figure 6: Numerical multibody model of the entire vehicle (left), detail of the bogie (right).

\section{Results}

Simulations have been performed in order to evaluate the stability of the vehicle: the rollers velocity has been increased since the critical speed has been reached.

Using the single suspended wheelset, it has been possible to determine the limit cycle diagrams (velocity-amplitude of oscillation) for different configuration (load/ conicity/ stiffness, see [13]).
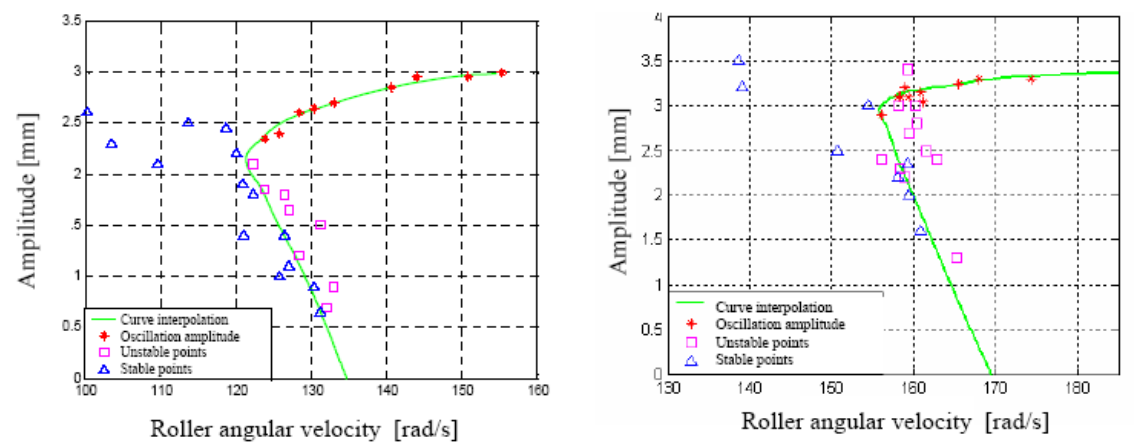

Figure 7: Limit cycles of instability obtained with conicity 0.3 (left) and 0.05 $\operatorname{rad}$ (right).

In this case the haunting motion of the wheelset has been excitated with lateral impulsive forces of different amplitude. If the resulting oscillations are damped, the motion is stable; otherwise a fixed amplitude oscillation occurs: the amplitude value defines the upper limit cycle. The lower curve of the limit cycle is defined by those amplitude values which delimit the stable by the unstable region of the velocity-amplitude diagram.

Figure 7 shows the experimental limit cycles obtained with 0.3 and $0.05 \mathrm{rad}$ conical profiles. It is evident that in reality it is possible to have instability even at lower velocity than the critical speed (intersection of the diagram with the $\mathrm{x}$ 
axis). A new limit value is defined: the limit speed; between the limit speed and the critical speed instability occur only if the excitation is over a certain amplitude (lower limit cycle). The experimental values have been compared with the numerical model, and results are shown on table 2. Values of the critical speed and of the limit speed can be predicted with a very good approximation. In order to obtain an accurate value for the amplitude f oscillation, it is necessary to use a non-linear model for the springs in the shear direction; in fact large oscillations occur and use of linear stiffness in not sufficient.

Table 2: $\quad$ Numerical/experimental comparison conicity 0.3 .

\begin{tabular}{|c|c|c|c|}
\hline & Experimental & Numerical & $\%$ Difference \\
\hline \multicolumn{4}{|c|}{ Linear stiffness model } \\
\hline Critical speed [m/s] & 23.2 & 23.3 & $0.8 \%$ \\
\hline Limit speed $[\mathrm{m} / \mathrm{s}]$ & 21.1 & 21.8 & $3.3 \%$ \\
\hline Oscillation amplitude [mm] & 2.8 & 3.2 & $12.5 \%$ \\
\hline \multicolumn{4}{|c|}{ Non linear stiffness model } \\
\hline Critical speed $[\mathrm{m} / \mathrm{s}]$ & 23.2 & 23.3 & $1.5 \%$ \\
\hline Limit speed $[\mathrm{m} / \mathrm{s}]$ & 21.1 & 22.2 & $5.6 \%$ \\
\hline Oscillation amplitude [mm] & 2.8 & 2.8 & $0.0 \%$ \\
\hline
\end{tabular}

\subsection{Test performed on the bogie}

Simulation performed on the bogie have are synthesized on table 3 using a high conicity wheelset (to simulate won profiles) and different axle loads; results are indicated in 1:5 scale. In this case, due to the high stiffness, the limit cycles are "compacted": the distance between limit and critical velocity is small.

Table 3: $\quad$ Experimental results with different axle load (conicity 0.3).

\begin{tabular}{|c|c|c|c|c|c|c|}
\hline Velocity & Axle load & \multicolumn{2}{|c|}{ Acceleration } & \multicolumn{2}{|c|}{ Displacement } & Frequency \\
\hline$[\mathrm{m} / \mathrm{s}]$ & {$[\mathrm{Kg}]$} & \multicolumn{2}{|c|}{$\left[\mathrm{m} / \mathrm{s}^{2}\right]$} & \multicolumn{2}{|c|}{$[\mathrm{mm}]$} & {$[\mathrm{Hz}]$} \\
\hline & & $\mathrm{X}$ & $\mathrm{Y}$ & $\mathrm{X}$ & $\mathrm{Y}$ & \\
\hline 40 & 42 & 0.069 & 6.32 & 0.6 & 5.5 & 5.5 \\
\hline 35 & 47 & 0.501 & 2.73 & 0.32 & 1.74 & 6.3 \\
\hline 30 & 52 & 0.107 & 4.66 & 0.9 & 3.9 & 5.2 \\
\hline 27.5 & 52 & 0.117 & 5.01 & 1.1 & 4.7 & 5.5 \\
\hline
\end{tabular}

Therefore the study has been performed considering the unstable behaviour. The axle load evidence a negative effect over the stability. This effect is complementary to the effect of wheel-rail friction. Unfortunately the friction coefficient change during the test, in particular, if instability occurs for long period, the friction coefficient increases. The friction coefficient has been measured only statically at the beginning of the test (value 0.38 ) and numerical simulations are performed using this value. During the test, when the friction increases higher amplitude oscillations can be observed and explains differences 
respect the numerical model (table 4). Numerical Analysis shows the same behaviour as shown on figure 8: the instability is reached at almost the same velocity of the rollers (error lower than 10\%). The experimental results show a more unstable behaviour (except at $35 \mathrm{~m} / \mathrm{s}$ ).
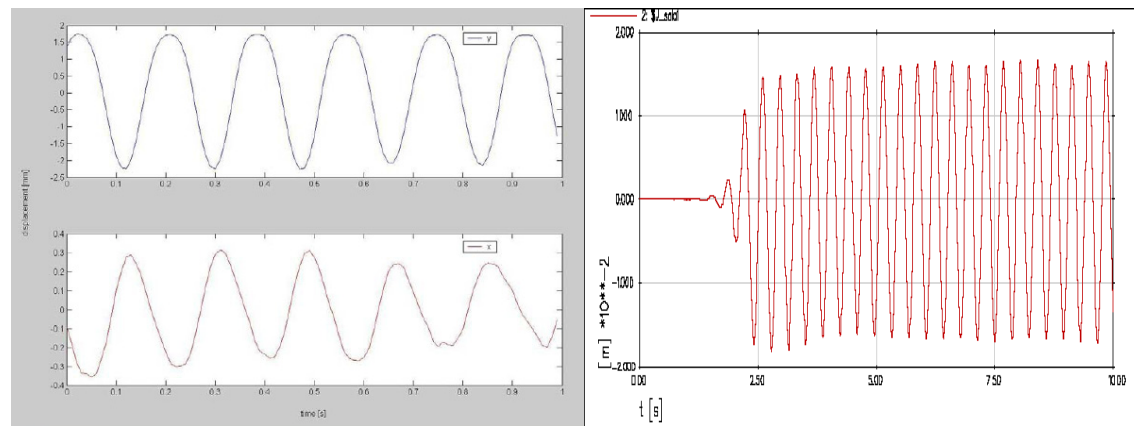

Figure 8: Experimental (left) and numerical behaviour (right) of the first wheelset at $40 \mathrm{~m} / \mathrm{s}$.

Large difference on the displacement and acceleration can be explained by the different friction coefficient and by the fact that suspension non-linearity has been neglected, and this could not be appropriate for large displacements.

Table 4: $\quad$ Numerical/experimental comparison (lateral direction).

\begin{tabular}{|c|c|c|c|c|}
\hline Velocity & Axle load & Y Acceleration & Y Displacement & Frequency \\
\hline$[\mathrm{m} / \mathrm{s}]$ & {$[\mathrm{Kg}]$} & {$\left[\mathrm{m} / \mathrm{s}^{2}\right]$} & {$[\mathrm{mm}]$} & {$[\mathrm{Hz}]$} \\
\hline 40 & 42 & $-30.4 \%$ & $-36.3 \%$ & $30.4 \%$ \\
\hline 35 & 47 & $3.7 \%$ & $47.1 \%$ & $4.7 \%$ \\
\hline 30 & 52 & $-35.6 \%$ & $-31.3 \%$ & $20.7 \%$ \\
\hline 27.5 & 52 & $-37.6 \%$ & $-30.6 \%$ & $18.2 \%$ \\
\hline
\end{tabular}

\section{Conclusions}

The paper shows the activity performed on the Roller Rig realized at Politecnico di Torino, both on a single suspended wheelset than on a complete two-axle bogie. The tests performed on a single wheelset show a very good agreement with numerical results, and it is possible to evaluate not only the critical speed, but also the limit cycles of instability. The multibody numerical model allows an accurate identification of all the parameters and non-linearity. For this reason this system (single wheelset) can be adopted to perform investigations on the wheelrail contact in order to improve the contact model. A high speed bogie is considered, and, due to the high stiffness in the primary suspension, the limit cycle vanishes. Amplitude of oscillation in strongly influenced by non-linearity (gap, friction) and in this case, due to the complexity of the model it is not easy to identify all the parameters with the same accuracy of the case of the single 
wheel set. Anyway, results are useful in relative terms in order to perform optimisation on the suspension characteristics.

\section{References}

[1] Iwnicki S.D., 1998, "Roller rig scaling”, European Roller Rig Meeting, Manchester 27-8-1998.

[2] Jaschinski A., 1990, "On the application of similarity laws to a scaled railway bogie model", DLR Institut für Dynamik der flugsysteme, Oberpfaffenhofen (Germany).

[3] Iwnicki S.D., Wickens A. H., 1998, "Validation of a MATLAB Railway Vehicle Simulation Using a Scaled Roller Rig", Vehicle System Dynamics, pp. 257-270.

[4] A. Jaschinski, H. Chollet, S. Iwnicky, A. Wickens and J. von Wurzen, "The application of roller rigs to railway vehicle dynamics", Vehicle System Dynamics, No. 31, pp. 345 - 392, 1999.

[5] R.V. Dukkipati " A parametric study of the lateral stability of a rail bogie on a roller rig”, Proc. Inst. Mech. Engrs. Part F, Vol. 213, pp. 39 -47, 1999.

[6] N. Bosso, A. Gugliotta, E. Napoli, A. Somà, "Simulation of a scaled roller rig”, 5th ADAMS/Rail Users' Conference; Haarlem, Netherlands - May 10 th -11 th, 2000.

[7] N. Bosso, A. Gugliotta, A. Somà, "Progettazione di un banco prova in scala $1 / 5$ per analisi sperimentale di carrelli ferroviari " - XXIX AIAS Lucca, 2000.

[8] N. Bosso, A. Gugliotta, L. Gusman, A. Somà. "Simulazione del comportamento dinamico di una sala ferroviaria per Roller-Rig" - XXIX AIAS - Lucca, 2000.

[9] N. Bosso, A. Gugliotta, A. Somà, "Comparison of different scaling techniques for the dynamics of a bogie on roller rig"- 17th Symposium Dynamics of Vehicles on road and tracks - IAVSD 2001 - Technical University of Denmark. Copenhagen (Lyngby), August 20-24, 2001.

[10] N. Bosso, A. Gugliotta, A. Somà, "Introduction of a wheel-rail and wheelroller contact model for independent wheels in a Multibody code." ASME/IEEE Joint Rail Conference, Washington, DC, 22-24 April 2001.

[11] N. Bosso, A. Gugliotta, A. Somà, "Dynamic and design of a 1/5 scaled roller-rig: simulation of wheel rail contact". Rolling Contact Fatigue. Brescia, 2002.

[12] N. Bosso, A. Gugliotta, A. Somà, "Experimental validation of a wheel-rail contact model using a scaled roller rig." 1st MSC-ADAMS Conference. London UK. 2002.

[13] N. Bosso, A. Gugliotta, A. Somà, "Stability analysis of a single suspended wheelset on a $1 / 5$ scale roller rig -comparison of experimental test versus multibody numerical simulations.” PRORAIL 2003 - ZILINA (Slovak Republic). 